\title{
The Measurement of Apolipoprotein A-I and A-II Levels in Men and Women by Immunoassay
}

\author{
Marian C. Cheung and John J. Albers \\ From the Department of Medicine and the Northwest Lipid Research Clinic, \\ School of Medicine, University of Washington, Seattle, Washington 98195
}

A B S T R A C T To study apolipoprotein A-II, a simple, precise, and accurate immunodiffusion assay was developed and applied in a population sample of industrial employees. Apolipoprotein A-II (A-II) did not increase with age in men $(r=-0.20, n=172)$, but showed a slight increase with age in women $(0.1$ $\mathrm{mg} / \mathrm{dl}$ per $\mathrm{yr}, r=0.20, n=188$ ). A-II correlated significantly with apolipoprotein A-I (A-I) $(r=0.71)$ and high density lipoprotein (HDL) cholesterol (men, $r=0.64$; women, $r=0.49$ ). The A-I/A-II ratio was significantly related to HDL cholesterol (men, $r=0.29$; women, $r=0.44)$. Women on no medication $(n=92)$ had A-II levels similar to men $(34 \pm 5$ and $33 \pm 5$ $\mathrm{mg} / \mathrm{dl}$, mean $\pm \mathrm{SD}$, respectively), whereas women on oral contraceptives or estrogens had significantly higher levels $(39 \pm 6 \mathrm{mg} / \mathrm{dl}, n=75, P<0.01)$. The plasma A-I/A-II weight ratio was $3.6 \pm 0.4$ for men and $3.8 \pm 0.5$ for women. In the $d=1.10-1.21$ subfraction, both males and females had similar A-I, A-II, and HDL cholesterol levels (men: mean, 97, 27, and $32 \mathrm{mg} / \mathrm{dl}$, respectively; women: mean, 104,28 , and $36 \mathrm{mg} / \mathrm{dl}$, respectively). Women had approximately twice the amount of A-I, A-II, and HDL cholesterol than men in the $d=1.063-1.10$ fraction (men: mean, 10,2 , and $10 \mathrm{mg} / \mathrm{dl}$, respectively; women: mean, 24 , 4 , and $19 \mathrm{mg} / \mathrm{dl}$, respectively). The A-I/A-II weight ratio in the $d=1.063-1.10$ fraction (men, 5.1 \pm 0.7 ; women, $6.1 \pm 1.3)$ was significantly greater $(P<0.01)$ than that in the $d=1.10-1.21$ fraction (men, 3.7 \pm 0.2 ; women, $3.8 \pm 0.2$ ). Furthermore, the weight ratio of cholesterol to total apoprotein $\mathrm{A}$ in the $d=1.063$ 1.10 fraction (men, $0.75 \pm 0.09$; women, $0.67 \pm 0.05$ ) was significantly higher $(P<0.01)$ than that found in the $d=1.10-1.21$ fraction (men, $0.26 \pm 0.04$, women, 0.28

A preliminary report of part of this work was presented at the 49th Annual Scientific Meeting of the American Heart Association in Miami, Fla. and was published in abstract form in 1976. Circulation. 54 (Suppl 2): 367.

Received for publication 21 July 1976 and in revised form 10 March 1977. \pm 0.05 ). Thus, the compositions of HDL hydrated density subclasses are significantly different from each other. These results suggest that the differences in HDL between men and women are due primarily to differences in the relative proportions of HDL subclasses rather than to the intrinsic differences in HDL structure.

\section{INTRODUCTION}

High density lipoproteins (HDL), ${ }^{1}$ via their interaction with lecithin-cholesterol acyltransferase, play a central role in cholesterol transport and metabolism (1). Most HDL molecules contain two major polypeptides, A-I and A-II (2-5). Although apolipoprotein A-I (A-I) has been shown to activate the lecithin-cholesterol acyltransferase enzyme (6), a specific functional role of apolipoprotein A-II (A-II) has yet to be documented. A simple, specific, and accurate method for quantitation of A-II has been needed to clarify its role in HDL structure and metabolism. The present investigation describes a simple, yet precise and accurate, radial immunodiffusion assay for human plasma A-II. Furthermore, this assay has been applied to characterize the relationship of A-II values to HDLcholesterol and A-I, age, sex, hormonal status, and lipid values and to assess the A-II levels in plasma ultracentrifugal fractions.

\section{METHODS}

Antigen and antisera preparation. HDL of $d=1.125-$ 1.21 was isolated from individual donors by ultracentrifugation. The nonprotein solvent density of plasma from a normolipidemic fasting adult was adjusted to $1.21 \mathrm{~g} / \mathrm{ml}$ with solid $\mathrm{KBr}$. Ultracentrifugation was then performed in a $60 \mathrm{Ti}$ rotor (Beckman Instruments, Inc., Palo Alto, Calif.)

${ }^{1}$ Abbreviations used in this paper: A-I, apolipoprotein A-I; A-II, apolipoprotein A-II; HDL, high density lipoprotein; PAGE, polyacrylamide gel electrophoresis; RID, radial immunodiffusion; SDS, sodium dodecyl sulfate; TMU, 1,1,3,3-tetramethylurea. 
at $50,000 \mathrm{rpm}$ at $10^{\circ} \mathrm{C}$ for $28 \mathrm{~h}$. The top $10 \mathrm{ml}$ of each tube was diluted to $1.125 \mathrm{~g} / \mathrm{ml}$ with $1 \mathrm{mM}$ disodium EDTA, pH 7.4, and then recentrifuged at $50,000 \mathrm{rpm}$ for $26 \mathrm{~h}$. After removing the top one-third by tube slicing, the bottom 1.125-1.21 HDL fraction was brought to $6 \mathrm{M}$ guanidine hydrochloride, and incubated at $37^{\circ} \mathrm{C}$ for $3 \mathrm{~h}$. It was then dialyzed against a $\mathrm{KBr}$ solution of $d=1.21$, and centrifuged at $50,000 \mathrm{rpm}$ for $24 \mathrm{~h}$. The resulting top fraction, containing primarily $\mathrm{A}-\mathrm{II}$ and the $\mathrm{C}$ apoproteins, was dialyzed

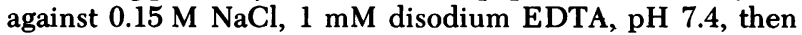
delipidated with ether-ethanol (7). This delipidated preparation was chromatographed on DEAE cellulose, equilibrated with $0.03 \mathrm{M}$ Tris- $\mathrm{HCl}$ ( $\mathrm{pH} 8.0$ ) containing $6 \mathrm{M}$ urea, and was then eluted with a linear gradient of $\mathrm{NaCl}$ from 0 to $0.125 \mathrm{M} \mathrm{NaCl}$ (8) to yield purified A-II.

Antisera to A-II was prepared by a method similar to that previously described for A-I (9).

A-II standards and quality control samples. A-II was prepared by centrifugation and ion-exchange chromatography as outlined above. The A-II preparation was dialyzed against

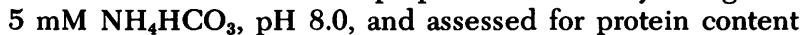
by the method of Lowry et al. (10). To assess the relationship between A-II and mass, duplicate amino acid analysis was performed on two A-II standards and the molar content of A-II was calculated on the basis of the molar content of alanine (11). Amino acid composition was determined with a JLC-5AH automatic analyzer (Joel [U.S.A.] Inc., Automated Analyzer Division, Crawford, N.J.) using a single column packed with Durrum DC-1A resin (Durrum Chemical Corp., Palo Alto, Calif.). Protein samples were hydrolyzed in $6 \mathrm{M} \mathrm{HCl}$ for $24 \mathrm{~h}$ at $110^{\circ} \mathrm{C}$ under $\mathrm{N}_{2}$. Elemental carbon, hydrogen, and nitrogen analysis was also performed on these preparations. The A-II standard was diluted with $8.4 \mathrm{M}$ 1,1,3,3-tetramethylurea (TMU) from Burdick \& Jackson Laboratories, Inc., Muskegon, Mich., and then $0.01 \mathrm{M}$ Tris$\mathrm{HCl}$ buffer, $\mathrm{pH} 8.0$, in $8 \mathrm{M}$ Ultra-pure urea (Tris-urea) from Schwarz/Mann Div., Becton, Dickinson \& Co., Orangeburg, N. Y., was added to give six different protein concentrations ranging from 1.6 to $5.5 \mathrm{mg} / \mathrm{dl}$.

Quality control samples were prepared from three plasma pools. $0.5-\mathrm{ml}$ aliquots of these plasma pools were stored in sealed Wheaton vials (Wheaton Scientific Div., Wheaton Industries, Millville, N. J.) at $-20^{\circ} \mathrm{C}$ until the day of immunochemical analysis.

Plasma samples. Plasma samples were obtained after an overnight $(12-14 \mathrm{~h})$ fast from adult industrial employees participating in a population study of the prevalence of hyperlipoproteinemia being conducted at the Northwest Lipid Research Clinic, Seattle, Wash. The present sample of this population, selected independently of lipid levels, was nearly identical to that previously studied for plasma A-I levels (9). Venous blood was drawn in Vacutainer tubes (Becton, Dickinson \& Co., Rutherford, N.J.) containing disodium EDTA, $1 \mathrm{mg} / \mathrm{dl}$, according to standardized conditions (12), and promptly separated by low speed centrifugation at $4^{\circ} \mathrm{C}$. Plasma samples were stored at $-20^{\circ} \mathrm{C}$ with $0.05 \%$ (weight/volume) sodium azide in sealed Wheaton vials.

Radial immunodiffusion (RID) procedure. The RID procedure for the quantitation of A-II was similar to that described for A-I (9). A given volume of plasma or plasma fraction, usually $50 \mu \mathrm{l}$, was diluted with an equal volume of TMU and mixed. The TMU-plasma mixture was diluted with a fivefold volume of Tris-urea and incubated for a minimum of $30 \mathrm{~min}$ at room temperature. Agarose RID plates were prepared as previously described (13). Specifically, A-II antiserum was diluted to a desired concentration (1:12-1:18) with $0.02 \mathrm{M}$ Tris-HCl buffer, $\mathrm{pH} 8.0$, containing $0.15 \mathrm{M} \mathrm{NaCl}, 1 \mathrm{mM}$ disodium EDTA, $0.05 \%$ (weight/ volume) sodium azide, and $1 \%$ (weight/volume) bovine serum albumin. $11 \mathrm{ml}$ of diluted anti-A-II serum was heated to $55^{\circ} \mathrm{C}$ and added to an equal volume of $2 \%$ (weight/volume) melted agarose solution cooled to $55^{\circ} \mathrm{C}$. This antiserum-agarose solution was mixed thoroughly and immediately poured into a prewarmed $125 \times 125 \times 12-\mathrm{mm}$ glass dish precoated with $1 \%$ (weight/volume) silicone. The mixture was left to solidify on a level surface for approximately 30 min. 100 antigen wells of $1.8 \mathrm{~mm}$ diameter were punched out at $11-\mathrm{mm}$ intervals (center to center) using a brass needle. $4 \mu \mathrm{l}$ of each sample was added in duplicate wells chosen in different quadrants on the plates. Two different standard preparations with six dilutions per standard were added to each plate. The plates were placed in a humid chamber in a level position at $37^{\circ} \mathrm{C}$ until the precipitate rings attained their final size (48-72 h). The ring-shaped immunoprecipitates were measured in $0.1-\mathrm{mm}$ units using a micrometer lens (Bausch \& Lomb Inc., Rochester, N. Y.).

Lipid and lipoprotein analyses. Cholesterol and glyceride were analyzed with the Technicon AutoAnalyzer II (Technicon Instruments Corp., Tarrytown, N. Y.) $(12,14)$. For cholesterol analysis, the coefficient of variation was $<4 \%$ and accuracy was within $5 \%$ of the target value; for glyceride analysis, the coefficient of variation was $<5 \%$ and accuracy was within $10 \%$. To measure HDL cholesterol, $0.15 \mathrm{ml}$ of $1 \mathrm{M} \mathrm{MnCl}{ }_{2}$ and $0.12 \mathrm{ml}$ of $35 \mathrm{mg} / \mathrm{ml}$ heparin (Riker Laboratories, Northridge, Calif.) were added to a 3-ml aliquot of plasma, and cholesterol determination was performed on the supernatant fraction (12). A-I was analyzed by the RID method of Albers et al. (9).

The cholesterol and A-I and A-II contents of various ultracentrifugal fractions were determined. To prepare these fractions, fresh plasma from three to four donors of the same sex was pooled, and 4-ml aliquots were adjusted to the nonprotein solvent density of $1.10 \mathrm{~g} / \mathrm{ml}$ with solid $\mathrm{KBr}$, overlayered with $2 \mathrm{ml}$ of $\mathrm{KBr}$ solution of $d=1.10$, and centrifuged in a $40.3 \mathrm{Ti}$ rotor at $39,000 \mathrm{rpm}$ at $16^{\circ} \mathrm{C}$ for $48 \mathrm{~h}$. The top $2.5 \mathrm{ml}$ containing the $d \leq 1.10$ fraction was carefully aspirated with a Pasteur pipette, dialyzed against $0.15 \mathrm{M} \mathrm{NaCl}, 1 \mathrm{mM}$ disodium EDTA, pH 7.4 (saline-EDTA), and saved for cholesterol and A-I and A-II analyses. The bottom fraction, constituting the $d>1.10$ fraction, was either similarly dialyzed and retained for lipid and apolipoprotein analyses, or adjusted to $d=1.21 \mathrm{~g} / \mathrm{ml}$ with solid $\mathrm{KBr}$ and overlayered with approximately $2 \mathrm{ml}$ of $\mathrm{KBr}$ solution of $d=1.21$, and then centrifuged as before but for $28 \mathrm{~h}$. To prepare the $d=1.063-1.10$ fraction, the $d \leq 1.10$ fraction was diluted with $1 \mathrm{mM}$ disodium EDTA, pH 7.4, to a density of 1.063 , then overlayered with approximately $2 \mathrm{ml}$ of $\mathrm{KBr}$ solution of $d=1.063$ and centrifuged for $28 \mathrm{~h}$. The top $3.5 \mathrm{ml}$ of the $d=1.21$ spin and the bottom $3.5 \mathrm{ml}$ of the $d=1.063 \mathrm{spin}$ which contained the $d=1.10-1.21$ and $d=1.063-1.10$ fractions, respectively, were dialyzed against saline-EDTA and saved for cholesterol, A-I, and A-II analyses.

For preparation of the HDL fractions for polyacrylamide gel electrophoresis, the $d=1.063-1.10$ and $1.10-1.21$ fractions were recentrifuged at $d=1.10$ and 1.21 , respectively, for $40 \mathrm{~h}$ to remove traces of albumin.

Quantitation of A-I and A-II by polyacrylamide gel electrophoresis. Polyacrylamide disc gels of the size described by Kane et al. (15) were used.

The $d=1.063-1.10$ and $d=1.10-1.21$ HDL fractions, washed free of albumin, were delipidated by ether-ethanol (3:1), dried under nitrogen, and redissolved in a Tris-TMU

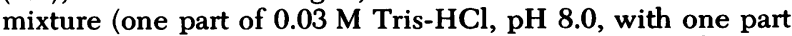
of stock TMU). A-I and A-II standards in which identity, purity, and mass had been established by amino acid analysis, elemental carbon, hydrogen, and nitrogen analysis, 


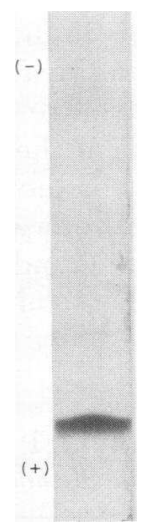

FIGURE 1 SDS polyacrylamide gel electrophoresis of A-II. $40 \mu \mathrm{g}$ of A-II was preincubated with $1 \%$ SDS and $1 \% \beta$ mercaptoethanol for $2 \mathrm{~min}$ at $100^{\circ} \mathrm{C}$.

sodium dodecyl sulfate (SDS) polyacrylamide gel electrophoresis, and Lowry protein determination were similarly dissolved. Four different volumes (80-200 $\mu \mathrm{l}$ ) of apo A-I $(50-150 \mu \mathrm{g})$ and apo A-II $(20-60 \mu \mathrm{g})$ standards, and two different volumes of each HDL fraction were applied on the gels. Bromophenol blue and sucrose solution (80\% weight/ volume) were added to each sample and mixed. Electrophoresis and gel staining were carried out according to the method of Kane et al. (15). Gels were destained in $7 \%$ acetic acid in a circulating destainer (Hoefer Scientific Instruments, San Francisco, Calif.) until a clear background was attained. Densitometric scanning was performed on an integrated densitometer (Quick Scan and Quick Quant II, Helena Laboratories, Beaumont, Tex.).

Statistical analyses. The significance of statistical differences between mean values of various parameters were analyzed using the Student's $t$ test. Pearsons' correlation coefficient, $r$, was used to show the degree of linear association between the different variables. The significance of $r$ is found from the $t$-distribution using the formula $t_{n-2}$ $=r \sqrt{(n-2) /\left(1-r^{2}\right)}$ (16). Correlation coefficients and frequency distributions were analyzed with a standard Statistical Package for Social Sciences program (17) on the Control Data Corp. 6400 series (Minneapolis, Minn.) at the University of Washington computer center.

\section{RESULTS}

Characterization of A-II standard. Amino acid analysis of three separate preparations of A-II were nearly identical to that published (with no detectable histidine or arginine) (11). Furthermore, the A-II preparation migrated as a single band in SDS gel electrophoresis (18) with an apparent molecular weight of the reduced form of 8,700 (Fig. 1). $1 \mathrm{mg}$ of A-II determined by the Lowry method was equivalent to $1.04 \mathrm{mg}$ by elemental carbon, hydrogen, and nitrogen analysis and $0.96 \mathrm{mg}$ by amino acid analysis. Therefore, the Lowry protein value was used to assess A-II mass.

Immunoassay validation. The rabbit anti-human A-II sera produced a single precipitate arc of identity between delipidated HDL (apo-HDL) and purified
A-II in gel diffusion plates, but did not react with human serum albumin, apoproteins A-I, C-I, C-II, C-III, $\mathrm{D}$, or the "arginine-rich peptide". The relationship between the square of the diameter of the precipitate ring and the amount of A-II was linear over the range of $0.8-7.2 \mathrm{mg} / \mathrm{dl}(r=0.995 \pm 0.004, n=36)$. The diameters of the precipitate rings ranged from $3.2 \mathrm{~mm}$ for the $0.8-\mathrm{mg} / \mathrm{dl}$ standard to a maximum of $8.5 \mathrm{~mm}$ for the $7.2-\mathrm{mg} / \mathrm{dl}$ standard.

Apo-A-II standards diluted in either Tris buffer, Tris-urea, or TMU plus Tris-urea gave precipitate rings of comparable diameters, indicating that neither 7.2 $\mathrm{M}$ urea nor $0.84 \mathrm{M}$ TMU affected final precipitate ring size (Fig. 2). When various dilutions of plasma were prepared separately in each of these diluents, only TMU plus Tris-urea gave a dilution curve parallel to the standard (Fig. 3), whereas in Tris buffer and Tris-urea, the apparent A-II concentration increased with increasing dilution. Thus, combination of TMU and Tris-urea is a valid diluent for plasma samples.

A-II values obtained on 48 plasma samples delipidated with ether-ethanol (3:1) were slightly lower (93 $\pm 9 \%$ ) than those obtained by the standard RID method using undelipidated plasma in the presence of TMU. In an additional experiment, A-II standard was added to each of two plasma pools. Eight aliquots of each of these mixtures of plasma and A-II were delipidated. The recovery of the added A-II averaged $94 \pm 6 \%$. Thus, taking into consideration the approximate $6 \%$ loss of A-II which occurred during delipidation, the A-II values obtained on delipidated plasma were comparable to those obtained by the TMU procedure.

The effect of freezing and thawing on the plasma A-II level by RID was also studied. Six plasma samples were stored in sealed Wheaton vials for $4 \mathrm{wk}$ at

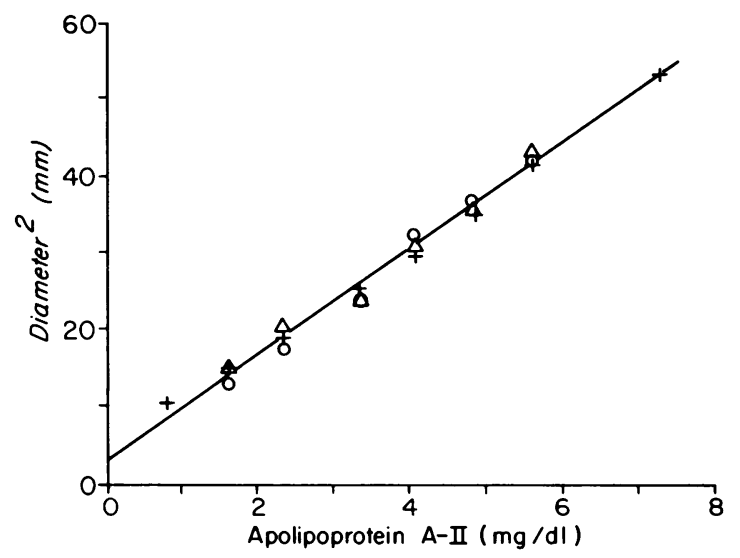

FIGURE 2 Relationship of precipitate ring size to A-II concentration. $50 \mu \mathrm{l}$ of stock A-II standard in $0.01 \mathrm{M}$ Tris$\mathrm{HCl}$ buffer, pH 8, diluted with $450 \mu$ l of $0.01 \mathrm{M}$ TrisHCl buffer, pH $8(O)$, or Tris buffer with $8 \mathrm{M}$ urea, designated Tris-urea $(\Delta)$, or with $50 \mu$ l TMU plus $400 \mu$ l Trisurea $(x)$. 


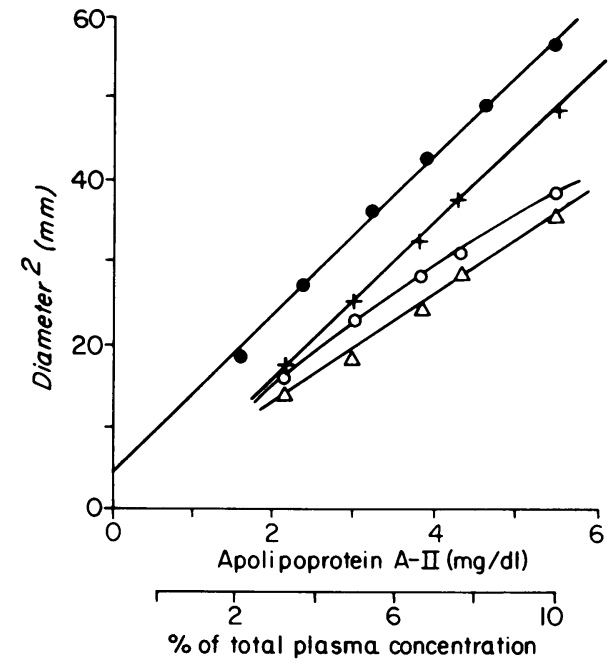

Figure 3 Comparison of plasma in various diluents with the A-II standard. $50 \mu$ l of whole plasma or plasma dilutions diluted with $450 \mu \mathrm{l}$ of $0.01 \mathrm{M}$ Tris- $\mathrm{HCl}$ buffer, $\mathrm{pH} 8(\mathrm{O})$, or Tris buffer with $8 \mathrm{M}$ urea, designated Tris-urea $(\triangle)$, or with $50 \mu \mathrm{l}$ TMU plus $400 \mu \mathrm{l}$ Tris-urea $(\times)$ as compared to A-II standard diluted with TMU plus Tris-urea (O).

$4^{\circ} \mathrm{C}$ or $-20^{\circ} \mathrm{C}$. During this time the frozen samples were thawed for $4-8 \mathrm{~h}$ once weekly. The A-II concentration of the samples repeatedly frozen and thawed agreed within $5 \%$ with the A-II levels of the corresponding aliquots stored at $4^{\circ} \mathrm{C}$.

An assessment of between-assay reproducibility was also performed by including aliquots of the three quality control pools in each assay. The means and SD of these pools were as follows: $24.8 \pm 1.5 \mathrm{mg} / \mathrm{dl}$, $n=32 ; 33.7 \pm 1.2 \mathrm{mg} / \mathrm{dl}, n=25 ;$ and $40.9 \pm 1.6 \mathrm{mg} / \mathrm{dl}$, $n=25$. Hence, the between-assay coefficient of variation ranged from 4 to $6 \%$.

A-I, A-II, and cholesterol content in ultracentrifugal fractions. Plasma ultracentrifugal fractions from six male and six female pools were analyzed for A-I, A-II, and cholesterol (Tables I and II). Women had approximately twice the amount of A-I, A-II, and HDL cholesterol than men in the $d=1.063-1.10$ fraction. In contrast, women had only slightly more A-I, A-II, and HDL cholesterol than men in the $d=1.10$ 1.21 fraction. The A-I/A-II weight ratio in the $d$ $=1.063-1.10$ fraction was significantly greater $(P$ $<0.01$ ) than that found in the $d=1.10-1.21$ fraction for both men and women. Furthermore, the weight ratio of cholesterol to apoprotein $\mathrm{A}$ in the $d=1.063$ 1.10 fraction (men, $0.75 \pm 0.09$; women $0.67 \pm 0.05$ ) was significantly higher $(P<0.01)$ than that found in the $d=1.10-1.21$ fraction (men, $0.26 \pm 0.04$; women, 0.28 $\pm 0.05)$. The A-I/A-II ratio or cholesterol/apoprotein A ratio was not significantly different between men and women for either the $d=1.063-1.10$ fraction or the $d=1.10-1.21$ fraction.
The A-I and A-II levels in the $d<1.10$ fraction was nearly identical to that in the $d=1.063-1.10$ fraction, indicating that on the average only $0.7 \%$ of the total A-I and A-II was found in the $d<1.063$ fraction. A similar comparison between the $d=1.10-1.21$ fraction and the $d>1.10$ fraction indicates that whereas $2.7 \%$ of total plasma A-II was found in the $d>1.21$ fraction, approximately $10 \%$ of total plasma A-I was found in this fraction.

TABLE I

A-I and A-II Content in Ultracentrifugal Fractions

\begin{tabular}{|c|c|c|c|c|}
\hline & \multicolumn{4}{|c|}{ Ultracentrifugal fractions* } \\
\hline & $d<1.10$ & $\begin{aligned} d & =1.063 \\
& -1.10\end{aligned}$ & $\begin{array}{c}d=1.10 \\
-1.21\end{array}$ & $d>1.10$ \\
\hline \multicolumn{5}{|l|}{ Males } \\
\hline \multirow[t]{7}{*}{ A-I, $m g / d l$} & 12.3 & 9.0 & 79.0 & 92.0 \\
\hline & 10.4 & 10.3 & 110.2 & 120.9 \\
\hline & 9.7 & 10.7 & 101.3 & 114.0 \\
\hline & 14.3 & 14.2 & 96.8 & 109.9 \\
\hline & 13.4 & 11.2 & 98.9 & 111.4 \\
\hline & 6.3 & 6.6 & 96.8 & 105.2 \\
\hline & $11.1 \pm 2.91$ & $10.3 \pm 2.5$ & $97.2 \pm 10.2$ & $108.9 \pm 9.8$ \\
\hline \multirow[t]{7}{*}{$\mathrm{A}-\mathrm{II}, m g / d l$} & 2.6 & 2.1 & 23.4 & 22.8 \\
\hline & 2.4 & 2.2 & 29.0 & 29.2 \\
\hline & 1.9 & 1.9 & 27.3 & 29.0 \\
\hline & 2.5 & 2.7 & 26.1 & 26.1 \\
\hline & 2.4 & 1.8 & 25.8 & 28.4 \\
\hline & 1.1 & 1.4 & 27.9 & 29.1 \\
\hline & $2.2 \pm 0.6$ & $2.0 \pm 0.4$ & $26.6 \pm 2.0$ & $27.4 \pm 2.6$ \\
\hline \multirow{7}{*}{$\begin{array}{l}\text { A-I/A-II, } \\
\text { weight ratio }\end{array}$} & 4.7 & 4.3 & 3.4 & 4.0 \\
\hline & 4.3 & 4.7 & 3.8 & 4.1 \\
\hline & 5.1 & 5.6 & 3.7 & 3.9 \\
\hline & 5.7 & 5.3 & 3.7 & 4.2 \\
\hline & 5.6 & 6.2 & 3.8 & 3.9 \\
\hline & 5.7 & 4.7 & 3.5 & 3.6 \\
\hline & $5.2 \pm 0.6$ & $5.1 \pm 0.7$ & $3.7 \pm 0.2$ & $4.0 \pm 0.2$ \\
\hline \multicolumn{5}{|l|}{ Females } \\
\hline \multirow[t]{7}{*}{ A-I, $m g / d l$} & 17.0 & 18.0 & 113.7 & 121.1 \\
\hline & 23.7 & 21.7 & 108.9 & 116.3 \\
\hline & 21.9 & 21.8 & 91.3 & 107.1 \\
\hline & 28.0 & 28.8 & 109.0 & 114.6 \\
\hline & 24.5 & 28.8 & 105.3 & 108.2 \\
\hline & 24.8 & 24.1 & 98.4 & 112.7 \\
\hline & $23.3 \pm 3.7$ & $23.8 \pm 4.3$ & $104.4 \pm 8.2$ & $113.3 \pm 5.2$ \\
\hline \multirow[t]{7}{*}{ A-II, $m g / d l$} & 3.9 & 4.0 & 31.7 & 30.8 \\
\hline & 4.0 & 4.2 & 31.6 & 29.7 \\
\hline & 4.1 & 4.0 & 24.0 & 26.3 \\
\hline & 3.8 & 3.9 & 27.4 & 29.9 \\
\hline & 3.2 & 3.6 & 26.7 & 26.3 \\
\hline & 3.8 & 4.0 & 25.2 & 27.5 \\
\hline & $3.8 \pm 0.3$ & $3.9 \pm 0.2$ & $27.7 \pm 3.2$ & $28.4 \pm 2.0$ \\
\hline \multirow{7}{*}{$\begin{array}{l}\text { A-I/A-II, } \\
\text { weight ratio }\end{array}$} & 4.4 & 4.5 & 3.6 & 3.9 \\
\hline & 5.9 & 5.2 & 3.4 & 3.9 \\
\hline & 5.3 & 5.5 & 3.8 & 4.1 \\
\hline & 7.4 & 7.4 & 4.0 & 3.8 \\
\hline & 7.7 & 8.0 & 3.9 & 4.1 \\
\hline & 6.5 & 6.0 & 3.9 & 4.0 \\
\hline & $6.2 \pm 1.3$ & $6.1 \pm 1.3$ & $3.8 \pm 0.2$ & $4.0 \pm 0.1$ \\
\hline
\end{tabular}

* Each number represents apolipoprotein analysis on ultracentrifugal fractions from individual plasma pools. Each pool is made up of three to four different plasmas. t Mean \pm SD. 
TABLE II

Cholesterol Content in Ultracentrifugal Fractions

\begin{tabular}{|c|c|c|}
\hline \multirow{2}{*}{$\begin{array}{l}\text { Ultracentrifugal } \\
\text { fractions }\end{array}$} & \multicolumn{2}{|c|}{ Cholesterol* $^{*}$} \\
\hline & Male & Female \\
\hline & \multicolumn{2}{|c|}{$m g / d l$} \\
\hline \multirow[t]{6}{*}{$d=1.063-1.10$} & 9.5 & 14.0 \\
\hline & 9.2 & 18.1 \\
\hline & 8.4 & 17.6 \\
\hline & 14.0 & 23.9 \\
\hline & 8.6 & 19.3 \\
\hline & $9.9 \pm 2.3 \ddagger$ & $18.6 \pm 3.6$ \\
\hline \multirow[t]{7}{*}{$d=1.10-1.21$} & 25.7 & 32.8 \\
\hline & 31.5 & 31.7 \\
\hline & 28.2 & 28.1 \\
\hline & 37.0 & 46.0 \\
\hline & 38.9 & 39.2 \\
\hline & 32.4 & 38.9 \\
\hline & $32.3 \pm 5.0$ & $36.1 \pm 6.5$ \\
\hline
\end{tabular}

* Each number represents cholesterol analysis on ultracentrifugal fractions from individual plasma pools.

$\$$ Mean \pm SD.

Quantitation of A-I and A-II on plasma HDL fractions from two male and two female pools by the RID method was compared to an independent estimation of these apoproteins by polyacrylamide gel electrophoresis (PAGE) and quantitative densitometry. The concentration of A-I and A-II by the RID method was comparable to that obtained by the PAGE procedure for both the $d=1.10-1.21$ fraction and the $d=1.063$ 1.10 fraction (Table III). Furthermore, the A-I/A-II ratios for these HDL fractions were comparable to those obtained on the previous ultracentrifugal fractions (compare Tables I and III). Again, the A-I/A-II ratio in the $d=1.063-1.10$ fraction was significantly greater than that found in the $d=1.10-1.21$ fraction for both men and women, whereas the A-I/A-II ratio in either HDL fraction was not significantly different between men and women.

Plasma A-II levels in population study subjects. For men, the frequency distribution of plasma A-II values was approximately normal but slightly positively skewed (skewness, 0.59 ; kurtosis, 0.68 ) with a mean and median of $33 \mathrm{mg} / \mathrm{dl}$ (Table IV and Fig. 4). The 10th percentile cutpoint was $28 \mathrm{mg} / \mathrm{dl}$ and the 90 th percentile was $39 \mathrm{mg} / \mathrm{dl}$. The distribution of A-II levels for the 92 women taking no medication was approximately normal (skewness, 0.25; kurtosis, 0.02) with a mean and median of $34 \mathrm{mg} / \mathrm{dl}$. Their nonage adjusted percentile cutpoints were similar to men (10th percentile, $25 \mathrm{mg} / \mathrm{dl}$; and 90th percentile, 40 $\mathrm{mg} / \mathrm{dl}$ ). Women taking estrogen-containing medications had an A-II distribution shifted to higher values with a mean of $39 \mathrm{mg} / \mathrm{dl}$ and a $90 \mathrm{th}$ percentile cut- point of $45 \mathrm{mg} / \mathrm{dl}$. Specifically, women who had taken no medication for $2 \mathrm{wk}$ before blood drawing showed a significantly lower A-II level $(P<0.001)$ than women taking estrogen or combination estrogen-progestational preparations. However, no difference was evident in A-II level between the group taking estrogens alone versus those taking combination oral contraceptives.

Table $\mathrm{V}$ presents plasma A-II levels by age decade in population study subjects. Plasma A-II did not increase with age in men $(r=0.02)$, but showed a slight increase with age in all women $(0.1 \mathrm{mg} / \mathrm{dl}$ per $\mathrm{yr})$ $(r=0.20, P<0.003)$. This was restricted, however, to those taking no medication. Thus, whereas the A-II levels among women on no medication showed a significant positive correlation with age $(r=0.40, P$ $<0.001$ ), among women on estrogenic hormones A-Il did not increase significantly with age $(r=0.17, P$ $<0.07$, Table VI).

Correlation of plasma A-II with plasma A-I and lipid (Table VI). Plasma A-II was highly correlated with plasma A-I $(r=0.71$ for men and 0.72 for all women), and HDL cholesterol $(r=0.64$ for men and 0.49 for all women). The A-II HDL cholesterol correlation was stronger for women on hormones $(r=0.56)$ than for those on no medication $(r=0.39)$. A-I was highly correlated with HDL cholesterol for all four groups examined $(r=0.78-0.72)$. A-II was only weakly correlated with total cholesterol in both men and women ( $r=0.26$ for men, and 0.32 for all women). However, A-II was not correlated with non-HDL cholesterol (total cholesterol minus HDL cholesterol). A-II did not correlate with log triglyceride in men but was significantly related to triglyceride in women $(r=0.36, P<0.001)$. The A-I/A-II weight ratio was

TABLE III

A-I and A-II Content in HDL Fractions, Comparison of PAGE with RID*

\begin{tabular}{|c|c|c|c|c|c|c|c|}
\hline \multirow[b]{2}{*}{ Fraction } & \multirow[b]{2}{*}{ Sex } & \multicolumn{2}{|c|}{ A-I } & \multicolumn{2}{|c|}{ A-II } & \multicolumn{2}{|c|}{ A-I/A-II } \\
\hline & & RID & PAGE & RID & PAGE & RID & PAGE \\
\hline & & \multicolumn{2}{|c|}{$m g / d l$} & \multicolumn{2}{|c|}{$m g / d l$} & \multicolumn{2}{|c|}{ weight ratio } \\
\hline$d=1.10$ & $\mathbf{F}$ & 85.8 & 87.1 & 24.7 & 24.8 & 3.5 & 3.5 \\
\hline \multirow[t]{3}{*}{-1.21} & F & 96.2 & 99.3 & 28.1 & 30.2 & 3.4 & 3.3 \\
\hline & $\mathbf{M}$ & 88.6 & 90.0 & 24.2 & 25.7 & 3.7 & 3.5 \\
\hline & $\mathbf{M}$ & 90.5 & 79.3 & 25.3 & 22.8 & 3.6 & 3.5 \\
\hline$d=1.063$ & $\mathbf{F}$ & 16.6 & 13.7 & 2.5 & 1.9 & 6.6 & 7.2 \\
\hline \multirow[t]{3}{*}{-1.10} & $\mathbf{F}$ & 13.1 & 10.8 & 1.9 & 1.8 & 6.9 & 6.0 \\
\hline & $\mathbf{M}$ & 7.2 & 7.5 & 1.3 & 1.1 & 5.5 & 6.8 \\
\hline & $\mathbf{M}$ & 11.6 & 11.7 & 2.1 & 1.9 & 5.5 & 6.2 \\
\hline
\end{tabular}

* Each number represents apolipoprotein analysis on HDL fractions from individual plasma pools. Each pool is made up of three plasmas. 
TABLE IV

Plasma A-II and A-I and HDL-Cholesterol Levels in Population Study Subjects*

\begin{tabular}{|c|c|c|c|c|c|c|}
\hline Subject group & $n$ & A-II & A-I & HDL CH! & A-I/A-II & A-I/A-II\$ \\
\hline & & & $m g / d l$ & & weight ratio & molar ratio \\
\hline All males & 172 & $33 \pm 5$ & $120 \pm 20$ & $45 \pm 12$ & $3.6 \pm 0.4$ & $2.2 \pm 0.3$ \\
\hline All females & 188 & $36 \pm 6$ & $135 \pm 25$ & $55 \pm 13$ & $3.8 \pm 0.5$ & $2.3 \pm 0.3$ \\
\hline \multicolumn{7}{|l|}{ Females } \\
\hline No medication" & 92 & $34 \pm 5$ & $130 \pm 22$ & $54 \pm 11$ & $3.9 \pm 0.5$ & $2.4 \pm 0.3$ \\
\hline On estrogen & 19 & $39 \pm 5$ & $149 \pm 24$ & $61 \pm 12$ & $3.9 \pm 0.5$ & $2.4 \pm 0.3$ \\
\hline $\begin{array}{c}\text { On estrogen and } \\
\text { progesterone }\end{array}$ & 56 & $39 \pm 6$ & $140 \pm 26$ & $54 \pm 15$ & $3.6 \pm 0.5$ & $2.2 \pm 0.3$ \\
\hline
\end{tabular}

* Population study participants were selected independently of their lipid levels. Results are expressed as mean \pm SD in milligrams/deciliter with sample size $=n$.

f $\mathrm{CH}$ refers to cholesterol.

$\$$ Based on an A-I mol wt of 28,300 and an A-II mol wt of 17,400 .

"Refers to a sample of women from the population study who have taken no medication for 2 wk before blood drawing.

significantly correlated with HDL cholesterol in both men and women ( $r=0.29$ for men, 0.44 for all women, 0.55 for women not taking medications, and 0.38 for women on hormones).

\section{DISCUSSION}

The described RID assay for human plasma A-II is simple, specific, accurate, and precise. Like the re-

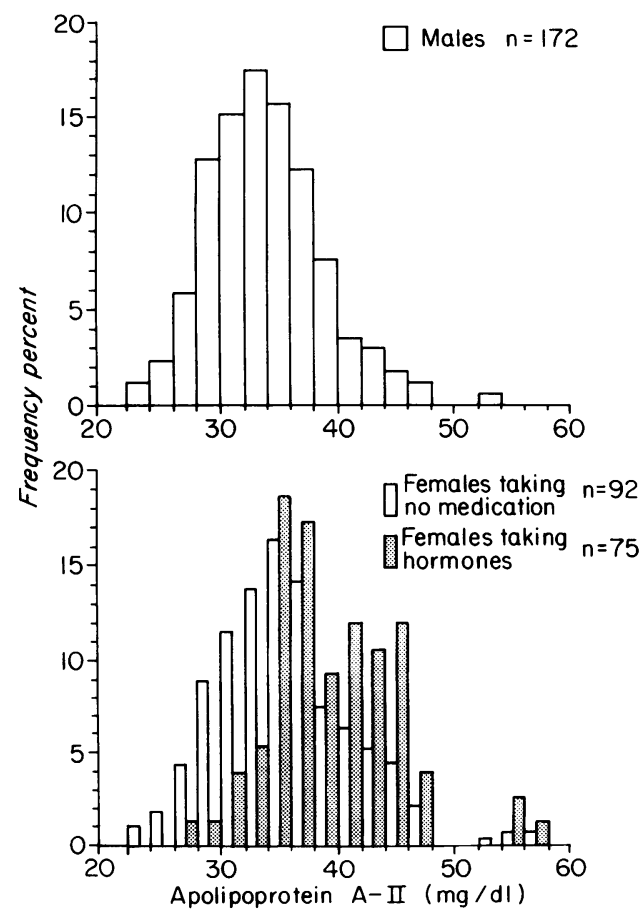

Figure 4 Distribution of plasma A-II in males, females taking no medication, and females taking hormones (oral contraceptives or estrogen). In the lower histogram, each bar on the abscissa corresponds to the same $2 \mathrm{mg} / \mathrm{dl} \mathrm{A-II}$ range within the same $2 \mathrm{mg} / \mathrm{dl}$ interval. cently described immunoassay for A-I, this assay, by using TMU plus Tris-urea in the diluent system, does not require prior extraction of lipids, utilizes only $50 \mu \mathrm{l}$ of plasma sample, and involves only a minimum of dilution. Furthermore, analysis of frozen or fresh plasma gives comparable results.

Curry et al. (19) recently reported a rapid electroimmunoassay for A-II which also did not require prior extraction of lipids. However, they reported A-II values of $78 \pm 17 \mathrm{mg} / \mathrm{dl}$ for men and $83 \pm 25 \mathrm{mg} / \mathrm{dl}$ for women, more than double the values which we found, i.e., $33 \pm 5$ for men and $36 \pm 6$ for women. The reason for these large differences is not apparent but may, in part, relate to differences in the antigen preparation or antibody specificity.

Our RID assay for A-I and A-II appeared accurate for HDL subfractions. An independent estimate of A-I and A-II by gel electrophoresis in both the $d=1.063$ 1.10 fraction and the $d=1.10-1.21$ fraction gave results comparable to the RID procedure. From the sum total of A-I and A-II recovered in the $d=1.063-1.21$ fraction (Table I) and assuming that A-I and A-II together account for $90 \%$ of the HDL protein, then the mean total protein content in HDL would be 151 $\mathrm{mg} / \mathrm{dl}$ for men and $178 \mathrm{mg} / \mathrm{dl}$ for women. The concentration of HDL protein estimated by sequential or analytical ultracentrifugation $(20-22)$ or by ratezonal ultracentrifugation (23) agrees well with these estimates. Therefore, the RID assays of the plasma A proteins as employed in this and the former study (9) appear reasonably accurate.

Our quantitative immunoassays indicated that the mean molar ratio of A-I to A-II for HDL is slightly greater than two. This result agrees well with Friedberg and Reynolds (24) who found a molar ratio of two to one by SDS gel electrophoresis of fluorescencetagged HDL apoproteins. Furthermore, our data is consistent with the radioimmunoassay data of Mao et al. 
TABLE V

Plasma A-II by Age in Population Study Subjects*

\begin{tabular}{|c|c|c|c|c|}
\hline \multirow[b]{2}{*}{ Age } & \multirow[b]{2}{*}{ All males } & \multirow[b]{2}{*}{ All females } & \multicolumn{2}{|c|}{ Females } \\
\hline & & & $\begin{array}{c}\text { No } \\
\text { medication } \ddagger\end{array}$ & $\begin{array}{c}\text { On } \\
\text { hormones }\end{array}$ \\
\hline $20-29$ & $34 \pm 4(27)$ & $35 \pm 6(82)$ & $32 \pm 4(37)$ & $38 \pm 5(41)$ \\
\hline $30-39$ & $33 \pm 5(53)$ & $35 \pm 7(33)$ & $34 \pm 5(19)$ & $40 \pm 7 \quad(9)$ \\
\hline $40-49$ & $34 \pm 5(55)$ & $37 \pm 5(44)$ & $36 \pm 4(28)$ & $41 \pm 6(11)$ \\
\hline $50-59$ & $33 \pm 5(35)$ & $38 \pm 6(27)$ & $37 \pm 2(11)$ & $39 \pm 6(13)$ \\
\hline $60-65$ & $35 \quad(2)$ & $45 \quad(2)$ & $48 \quad$ (1) & $41 \quad$ (1) \\
\hline
\end{tabular}

* Results are expressed as mean $\pm \mathrm{SD}$ in milligrams per deciliter with sample size in parentheses.

\$ Refers to a sample of women from the population study who have taken no medication for 2 wk before blood drawing.

(25) and agrees well with the ratio of A-I to A-II obtained by column chromatography $(3,4,26)$. All the above results, however, differ from the 1:1 molar ratio obtained by electroimmunoassay (19).

It has been reported that the molar ratio of A-I and A-II is the same for the two major HDL subclasses, i.e., $\mathrm{HDL}_{2}$ and $\mathrm{HDL}_{3}(24)$. We found that the molar ratio of A-I to A-II in the $d=1.063-1.10$ fraction (3.2 \pm 0.4 for men, $3.8 \pm 0.8$ for women) was significantly higher than that for the $d=1.10-1.21$ fraction (2.2 \pm 0.1 for men, and $2.3 \pm 0.1$ for women). The content of cholesterol in association with the total A protein in the lighter HDL density subclass was more than double that in the heavier density subclass. Furthermore, the ratio of A-I to A-II was positively correlated with HDL cholesterol levels. These results suggest that the major structural differences between the HDL hydrated density subclasses relate to the relative proportions of A-I and A-II. Since the composition of the HDL subclasses did not differ significantly between men and women, the differences observed in HDL composition between men and women, e.g., women's total HDL have higher cholesterol to protein ratio and higher A-I to A-II ratio, primarily reflect the differences in the relative amounts of the HDL subclasses rather than differences in HDL structure. It should be emphasized that our HDL subclasses as isolated in the angle rotor are operational definitions and do not directly correspond to the $F_{1.20} 3.5-9$ and $F_{1.20}$ 0-3.5 HDL subclasses as defined by the analytical ultracentrifuge (27). Since the HDL subclasses, as used in this study, exhibit hydrated density and size heterogeneity, it is reasonable to expect that additional HDL compositional subclasses are present within each hydrated density subclass.

We report tentative age- and sex-related normal values for plasma A-II levels. As one would predict from the close relationship found between A-I and A-II, like A-I, A-II did not increase with age in men, but showed a slight increase with age in women. The observation that women taking estrogens alone had higher A-II, A-I, and HDL cholesterol levels than women on no medication suggests that exogenous estrogens increase HDL levels. On the other hand, women on combination estrogen-progestational preparations had comparable HDL cholesterol, somewhat higher A-I, and significantly higher A-II than women on no medication. This suggests that the progestational components of the combination oral contraceptives modify the composition of the HDL, thus altering the estrogen-promoted HDL changes. Additional studies will be required to clarify the specific hormonal effects on whole HDL and, especially, HDL subclasses.

If as suggested, HDL facilitates the clearance of cholesterol from the arterial wall (28) and modulates the transendothelial transport of low density lipoprotein $(29,30)$, then high HDL levels or HDL compositional changes which increase HDL cholesterolbinding capacity may be protective against the progression of atherosclerosis. Recent epidemiological data have indicated an inverse relationship between HDL cholesterol levels and the prevalence of coronary heart disease (31). An above-average life expectancy was demonstrated for subjects with high levels of HDL cholesterol (32). Furthermore, women have lower risk for coronary disease and higher A-I to A-II ratios than men. Since A-I/A-II ratios are positively correlated with HDL cholesterol, factors which raise

TABLE VI

Correlation of Plasma A-II with Plasma A-I and Lipids*

\begin{tabular}{llccc}
\hline \multicolumn{1}{c}{ Relationship } & $\begin{array}{c}\text { All } \\
\text { males }(n=172)\end{array}$ & $\begin{array}{c}\text { All } \\
\text { females }(n=188)\end{array}$ & $\begin{array}{c}\text { Females, no } \\
\text { medication }(n=92)\end{array}$ & $\begin{array}{c}\text { Females on } \\
\text { hormones }(n=75)\end{array}$ \\
\hline A-II vs. A-I & 0.71 & 0.72 & 0.69 & 0.69 \\
A-II vs. HDL CH $\$$ & 0.64 & 0.49 & 0.39 & 0.56 \\
A-II vs. total CH & 0.26 & 0.32 & 0.43 & 0.23 \\
A-II vs. log TG $\$$ & $-0.06(0.202)$ & 0.36 & 0.43 & $0.26(0.011)$ \\
A-II vs. age & $-0.02(0.412)$ & $0.20(0.003)$ & 0.40 & $0.17(0.068)$ \\
\hline
\end{tabular}

* Correlation coefficient $(r)$ is followed by probability $(P)$ unless $P$ is $<0.001$.

‡ CH, cholesterol, TG, triglyceride. 
the A-I to A-II ratio may increase HDL cholesterolbinding capacity.

\section{ACKNOWLEDGMENTS}

We thank G. Russell Warnick and the Northwest Lipid Research Clinic Core Laboratory staff for assistance in lipid analysis. We are indebted to David Anderson and Dr. Alex Nichols, Donner Laboratory, Berkeley, Calif. for suggesting the use of guanidine $\mathrm{HCl}$ in the A-II isolation procedure and for performing the elemental carbon, hydrogen, and nitrogen analysis. We thank Dr. William R. Hazzard for his helpful suggestions and review of the manuscript.

These studies were supported by contract NIHV 12157A from the National Institutes of Health, Lipid Metabolism Branch.

\section{REFERENCES}

1. Glomset, J. A. 1968. The plasma lecithin:cholesterol acyltransferase reaction. J. Lipid Res. 9: 155-167.

2. Shore, V., and B. Shore. 1968. Some physical and chemical studies on two polypeptide components of highdensity lipoproteins of human serum. Biochemistry. 7: 3396-3403.

3. Scanu, A., J. Toth, C. Edelstein, S. Koga, and E. Stiller. 1969. Fractionation of human serum high density lipoprotein in urea solutions. Evidence for polypeptide heterogeneity. Biochemistry. 8: 3309-3316.

4. Albers, J. J., and F. Aladjem. 1971. Precipitation of ${ }^{125}$ I-labeled lipoprotein with specific polypeptide antisera. Evidence for two populations with differing polypeptide compositions in human high density lipoproteins. Biochemistry. 10: 3436-3442.

5. Kostner, G., and P. Alaupovic. 1972. Studies of the composition and structure of plasma lipoproteins. Separation and quantification of the lipoprotein families occurring in the high density lipoproteins of human plasma. Biochemistry. 11: 3419-3428.

6. Fielding, C. J., V. G. Shore, and P. E. Fielding. 1972. A protein cofactor of lecithin:cholesterol acyltransferase. Biochem. Biophys. Res. Commun. 46: 1493-1498.

7. Albers, J. J., and A. M. Scanu. 1971. Isoelectric fractionation and characterization of polypeptides from human serum very low density lipoproteins. Biochim. Biophys. Acta. 236: 29-37.

8. Baker, H. N., R. L. Jackson, and A. M. Gotto, Jr. 1973. Isolation and characterization of the cyanogen bromide fragments from the high-density apolipoprotein glutamine I. Biochemistry. 12: 3866-3871.

9. Albers, J. J., P. W. Wahl, V. G. Cabana, W. R. Hazzard, and J. J. Hoover. 1976. Quantitation of apolipoprotein A-I of human plasma high density lipoprotein. Metab. Clin. Exp. 25: 633-644.

10. Lowry, O. H., N. J. Rosebrough, A. L. Farr, and R. J. Randall. 1951. Protein measurement with the Folin phenol reagent. J. Biol. Chem. 193: 265-275.

11. Brewer, H. B., Jr., S. E. Lux, R. Ronan, and K. M. John. 1972. The amino acid sequence of apoLp Gln-II (apo A-II), an apolipoprotein isolated from the high-density lipoprotein complex. Proc. Natl. Acad. Sci. U. S. A. 69: 1304-1308.

12. Lipid Research Clinics Program Manual Laboratory Operations. 1974. Department of Health, Education and Welfare Publication No. (NIH) 75-628. Vol. 1.

13. Albers, J. J., and W. R. Hazzard. 1974. Immunochemical quantitation of the human plasma $L p(a)$ lipoprotein. Lipids. 9: 15-26.
14. AutoAnalyzer Manual. 1970. Technicon Instruments Corp., Tarrytown, N. Y.

15. Kane, J. P., T. Sata, R. L. Hamilton, and R. J. Havel. 1975. Apoprotein composition of very low density lipoproteins of human serum. J. Clin. Invest. 56: 16221634.

16. Snedecor, G. W., and W. G. Cochran. 1967. Statistical Methods. Iowa State University Press, Ames, lowa. 6th edition. 593 pp.

17. Klecka, W. R., N. H. Nie, and C. H. Hull. 1975. SPSS Primer: Statistical Package for the Social Sciences Primer. McGraw-Hill, Inc., New York. 134 pp.

18. Weber, K., J. R. Pringle, and M. Osborn. 1972. Measurement of molecular weights by electrophoresis on SDSacrylamide gel. Methods Enzymol. 26: 3-27.

19. Curry, M. D., P. Alaupovic, and C. A. Suenram. 1976. Determination of apolipoprotein $A$ and its constitutive A-I and A-II polypeptides by separate electroimmunoassays. Clin. Chem. 22: 315-322.

20. Levy, R. I., and D. S. Fredrickson. 1965. Heterogeneity of plasma high density lipoproteins. J. Clin. Invest. 44: 426-441.

21. Nichols, A. V. 1967. Human serum lipoproteins and their interrelationships. Adv. Biol. Med. Phys. 11: 109158.

22. Lindgren, F. T., G. L. Adamson, L. C. Jenson, and P. D. Wood. 1975. Lipid and lipoprotein measurements in a normal adult American population. Lipids. 10: 750-756.

23. Patsch, J. R., S. Sailer, G. Kostner, F. Sandhofer, A. Holasek, and H. Braunsteiner. 1974. Separation of the main lipoprotein density classes from human plasma by rate-zonal ultracentrifugation. J. Lipid Res. 15: 356366.

24. Friedberg, S. J., and J. A. Reynolds. 1976. The molar ratio of the two major polypeptide components of human high density lipoprotein. J. Biol. Chem. 251: 4005-4009.

25. Mao, S. J. T., A. M. Gotto, Jr., and R. L. Jackson. 1975. Immunochemistry of human plasma high density lipoproteins. Radioimmunoassay of apolipoprotein A-II. Biochemistry. 14: 4127-4131.

26. Schonfeld, G., B. Pfleger, and R. Roy. 1975. Structure of human high density lipoprotein reassembled in vitro. Immunoassay studies. J. Biol. Chem. 250: 7943-7950.

27. Lindgren, F. T., L. C. Jensen, and F. T. Hatch. 1972. The isolation and quantitative analysis of serum lipoproteins. In Blood Lipids and Lipoproteins: Quantitation, Composition, and Metabolism. G. J. Nelson, editor. WileyInterscience Div., John Wiley \& Sons, Inc. New York. 181-274.

28. Miller, G. J., and N. E. Miller. 1975. Plasma-high-density lipoprotein concentration and development of ischaemic heart-disease. Lancet. I: 16-19.

29. Stein, O., and Y. Stein. 1976. High density lipoproteins reduce the uptake of low density lipoproteins by human endothelial cells in culture. Biochim. Biophys. Acta. 431: 363-368.

30. Carew, T. E., T. Koschinsky, S. B. Hayes, and D. Steinberg. 1976. A mechanism by which high-density lipoproteins may slow the atherogenic process. Lancet. 2: 1315-1376.

31. Rhoads, G. G., C. L. Gulbrandsen, and A. Kagan. 1976. Serum lipoproteins and coronary heart disease in a population study of Hawaii Japanese men. N. Engl. J. Med. 294: 293-298.

32. Glueck, C. J., R. W. Fallat, F. Millett, P. Gartside, R. C. Elston, and R. C. P. Go. 1975. Familial hyper-alphalipoproteinemia: studies in eighteen kindreds. Metab. Clin. Exp. 24: 1243-1265. 